\title{
Predicting the outcome in elderly patients of hospital admission for acute care in Paris, France: construction and initial validation of a simple index
}

Mahmoud Zureik, Pierre Lombrail, Alain Davido, Jean-Louis Trouillet, Béatrice Tran, Albert Levy, Thierry Lang

\begin{abstract}
Objective - To develop a simple index able to identify at an early stage those elderly patients at high risk of requiring discharge to a residential or nursing home after admission to hospital for acute care. For these patients, early discharge planning might lead to a more effective management and reduce the length of hospitalisation.
\end{abstract}

Design, setting, and patients - This was a prospective study conducted in two teaching hospitals in Paris, France. A total of 510 consecutive patients was included. They were aged 75 years or more and had been admitted to acute medical care units through the emergency department.

Measurements - Demographic data, social support, physical disability, mental disability, and pathologic status were assessed shortly after admission (within 24-48 hours).

Main outcome measures - Outcome of hospitalisation was defined as discharge to home or residential/nursing home.

Results - The index, developed by multiple logistic regression, included six variables: the wish of patients' principal carer about their returning home after acute hospitalisation, presence of a chronic condition, ability to perform toileting, ability to know the name of the hospital or the city, their age, and their living arrangements. The sensitivity of the index in identifying patients at high risk of requiring discharge to a residential/nursing home was $74.4 \%$, the specificity $63.8 \%$, the positive predictive value was $57.8 \%$, and the negative predictive value was $80.6 \%$. Conclusions - The simple index, using data available very early in the course of hospitalisation, provides an accurate prediction of the hospitalisation outcome. The performance of the index should be tested in other populations and the practical benefits of risk screening should be assessed in a controlled trial to evaluate whether the intervention is useful and without any adverse effects.

(F Epidemiol Community Health 1997;51:192-198)

Elderly people are more often admitted to hospital and stay in hospital longer than the gen- eral population. ${ }^{12}$ They are frequently admitted through the emergency department. ${ }^{3}$ After an acute illness, hospitalisation is often an intermediate step before entering a nursing home or other special care settings. ${ }^{34}$ Early discharge planning for patients at high risk of requiring discharge to a residential/nursing home might lead to more effective planning process, ${ }^{5}$ reduce the length of hospital stay, ${ }^{6}$ and prevent unnecessary readmission or nursing home placement. ${ }^{7}$ In fact, the stay of elderly patients in hospitals can generally be divided into a medical stay followed by a social stay. ${ }^{89}$ In a French study, the mean social stay was almost nil when the patient returned home, but it could reach five days when he or she was discharged to a long term care facility because of a shortage of places in nursing homes. ${ }^{9}$

The main difficulty in introducing early discharge planning lies in the identification of patients at high risk of requiring discharge to a residential/nursing home. This assessment is needed very soon after admission so that the elderly patients can benefit rapidly from comprehensive and effective discharge planning that facilitates their timely discharge. Results of past research showed that no single factor consistently differentiated patients who could be discharged home from those discharged to an institution. ${ }^{10}$ Each one of the predisposing factors such as age, sex, marital status, living arrangements, and mental and physical status, was related to the discharge disposition in some of these studies, but not in all of them..$^{11-16}$

We therefore undertook a prospective study to develop an index that could predict the outcome of hospitalisation for elderly patients admitted through emergency departments. Our hypothesis was that it would be possible to produce a short index, based on a limited number of variables available shortly after admission. With such an instrument, geriatric and social service staff could be mobilised early during the hospital stay of those elderly patients who would be unable to return home after the acute hospitalisation and were at high risk of requiring discharge to a residential/nursing home.

Methods

Details of study design and procedures have been previously published. ${ }^{17}$ Briefly, data were prospectively collected for 510 consecutive 
patients aged 75 or more who had been admitted from home to acute medical care units through the emergency department of two teaching hospitals in Paris (Pitié-Salpêtrière and Bichat) during two two-month periodsDecember 1, 1991, to February 1, 1992 and May 1 to July 1, 1992. Patients directly admitted to an intensive care unit were excluded.

\section{DATA COLLECTION AT ADMISSION}

Trained research assistants interviewed the elderly patients within 24 hours of admission. Physical disability was evaluated by the sixitem activities of daily living (ADL) scale ${ }^{18}$ and the seven-item instrumental activities of daily living (IADL) scale. ${ }^{19}$ Mental disability at the time of interview was measured using the 10item short portable mental status questionnaire (SPMSQ). ${ }^{20}$ When information was not available because of impaired consciousness, the SPMSQ score was recorded as 0 (28 patients). The pathologic status on admission was assessed by the physicians in charge of the emergency departments. The International Classification of Diseases (9th revision), was used to classify the main causes of hospital admission. ${ }^{21}$ The presence of a chronic condition, suspected of being fatal or not within four years, and of an acute condition, suspected of being fatal or not within one month, was assessed by the physicians according to a modified MacCabe score. ${ }^{22}$ Patients' wishes about returning home and the wishes of their principal carer about their returning home after the acute hospitalisation were investigated by the emergency departments' social workers. The closest relative (the principal carer) of each patient was stated by the patient himself or by the staff in the case of unconsciousness or mental impairment. The wishes of the principal carer about the patient returning home was recorded within 48 hours of admission by interview or by phone.

Of the 510 elderly patients initially included, 93 were excluded from the analysis: 71 died during the acute hospitalisation and 22 were transferred within 24 hours of their admission to other acute care facilities. Thus, a total of 417 patients was included for analysis- 254 patients at the Bichat hospital, and 172 at the Pitié-Salpêtrière hospital. The patients' characteristics hardly differed between the two hospitals. ${ }^{17}$ Therefore, data from the two study groups were pooled. The most frequent medical conditions recorded by the physicians as the main reason for admission at the time of initial assessment were cardiovascular diseases (18.3\%), falls $(22.1 \%)$, neurological diseases $(17.6 \%)$, confusion and/or dementia $(9.2 \%)$, and respiratory diseases $(7.4 \%)$. The characteristics of the 417 patients are shown in table 1 .

OUTCOME OF HOSPITALISATION AND LENGTH OF STAY

The hospitalisation outcome and date of discharge were collected by the social workers on the medical units. The outcome of hos-
Table 1 Characteristics of the 417 patients aged 75 years or older admitted through the emergency department to two teaching hospitals in Paris

\begin{tabular}{|c|c|}
\hline Variables* & $\begin{array}{l}\text { Patients } \\
(n=417)\end{array}$ \\
\hline Sex (\% of women) & $\begin{array}{l}73.4 \\
84.3(5.5)\end{array}$ \\
\hline Age (y, mean (SD)) & $84.3(5.5)$ \\
\hline Living alone (\%) & 59.4 \\
\hline \multicolumn{2}{|l|}{ Marital status $(\%)$ : } \\
\hline Widowed & 55.5 \\
\hline Married & 22.4 \\
\hline Unmarried & 13.7 \\
\hline Divorced or separated & 8.4 \\
\hline \multicolumn{2}{|c|}{ Patient's wishes about returning home (\%): } \\
\hline Agreement & 80.8 \\
\hline Without opinion & 16.5 \\
\hline Opposition & 2.7 \\
\hline \multicolumn{2}{|c|}{ Principal carer's wishes about patient returning home (\%): } \\
\hline Agreement & 61.1 \\
\hline Without opinion & 20.7 \\
\hline Opposition & 18.2 \\
\hline \multicolumn{2}{|c|}{ Activities of daily living at admission (\%): } \\
\hline Independent in all activities & 26.4 \\
\hline Dependent in 1-3 activities & 20.6 \\
\hline Dependent in 4-6 activities & 53.3 \\
\hline \multicolumn{2}{|c|}{ Instrumental activities of daily living at admission (\%): } \\
\hline Independent in all activities & 20.6 \\
\hline Dependent in $1-3$ activities & 17.8 \\
\hline Dependent in $4-7$ activities & 61.6 \\
\hline \multicolumn{2}{|l|}{ Mental alteration $(\%) \dagger$ : } \\
\hline Absence (8-10 correct answers) & 46.1 \\
\hline Mild (6-7 correct answers) & 18.6 \\
\hline Moderate ( $4-5$ correct answers) & 13.5 \\
\hline Severe $(0-3$ correct answers $)$ & 21.8 \\
\hline \multicolumn{2}{|l|}{ Chronic condition (\%): } \\
\hline None & 10.9 \\
\hline Yes, non-fatal within $4 \mathrm{y}$ & 63.1 \\
\hline Yes, fatal within $4 \mathrm{y}$ & 26.0 \\
\hline \multicolumn{2}{|l|}{ Acute condition (\%): } \\
\hline None & 7.2 \\
\hline Yes, non-fatal within $1 \mathrm{mth}$ & 80.2 \\
\hline Yes, fatal within $1 \mathrm{mth}$ & 12.6 \\
\hline
\end{tabular}

* Missing data: 8 , living arrangements; 11 , patient's wishes; 16 , referent's wishes; 19, ADL score and IADL score; 9, mental alteration; and 13, chronic and acute conditions.

$t$ Classes adjusted for the level of education as defined by the Pfeiffer scale.

pitalisation was classified as "home" or "residential/nursing home". "Home" included patients discharged home with or without home care services and those discharged to the homes of relatives. "Residential/nursing home" included patients discharged to a skilled nursing facility, a long term care facility, or an intermediate care facility. At discharge, 248 patients $(59.5 \%)$ returned home and $169(40.5 \%)$ were discharged toward a residential/nursing home. The average length of stay for patients discharged to a residential/nursing home was 9 days longer than for patients who returned home $(22.3(13.3)$ days versus $13.3(10.7)$, respectively, $\mathrm{p}<0.001$ ).

\section{STATISTICAL METHODS}

Associations of independent variables with the outcome of hospitalisation were assessed with univariate logistic regression models. For multivariate analysis, a stepwise logistic regression was used. The following factors were included in the stepwise logistic regression:

1. All variables that were significant at a $p$ value of less than 0.15 in the univariate analyses -age, living arrangements, receiving home care services, patients' and principal carers' wishes about the patient returning home, ADL status, IADL status, mental disability, and presence of an acute condition fatal within one month and of a chronic condition fatal within four years. ${ }^{17}$ 
2. The non-significant variables suggested as being important in published reports (gender, marital status, and hospital type).

An examination of all possible two-way interactions between independent variables determined that none was significant. Variables were eliminated one at a time from the model based on likelihood ratio tests. Variables were eligible for inclusion in the final model if they were significantly associated with hospitalisation outcome at a $\mathrm{p}$ value $<00.05$.

All factors were used as categorical variables. The only continuous variable, age, was categorised into two groups ( $\leq 85$ and $>85$ years). For ordinal variables with more than two strata (eg principal carer's wishes about the patient returning home: agreement, without opinion, or opposition), linear trends in factors associated with discharge to a residential/nursing home were tested by likelihood ratio test. When the likelihood ratio test was not significant, we used the independent variable coded in ordinal scale.

Our aim was to construct a simple and quick to determine index. We thus tested each item of ADL, IADL, and SPMSQ as independent variables instead of global ADL, IADL, and SPMSQ scores. For each activity of ADL (bathing, toileting, eating, dressing, walking at home, continence) and IADL (using telephone, shopping, preparing food, using public transport, taking medication, housekeeping, handling finances), a score of 0 indicated independent performance for that activity and a score of 1 indicated dependence or in need of human assistance in performing it. For each item of SPMSQ, a score of 0 indicated a correct answer and a score of 1 an incorrect one.

When all statistically non-significant variables had been eliminated from the multivariate model, adjusted odds ratios (ORs) were computed from the estimated coefficients in the model. The fit of the logistic model was assessed by the Hosmer-Lemeshow goodness-offit $\chi^{2}$ test and by examining the distributions of the predicted probabilities within each group of type of discharge. ${ }^{23}$ The SAS statistical package was used for statistical analysis. ${ }^{24}$

DEVELOPMENT OF THE PROGNOSTIC INDEX

The fitted coefficients of the final model were used to assign a score to each patient. In order to assess the prognostic value of the index, we examined the distribution of the scores among patients discharged home and among those discharged to a residential/nursing home. There was a choice of threshold score over which a patient might be considered at high risk of discharge to a residential/nursing home. For each threshold, we could calculate the sensitivity (correct classification of patients who were discharged toward a residential/nursing home), the specificity (correct classification of patients discharged home), the predictive value of a positive test (proportion of patients predicted to be discharged to a residential/nursing home who were ultimately discharged to a residential/nursing home), the predictive value of a negative test (proportion of patients pre- dicted to be discharged home who were actually discharged home), and the total correct classification (true positives plus true negatives). The prognostic index had to identify patients at high risk of discharge to a residential/nursing home with the least possible chance of wrongly classifying as low risk a patient who was ultimately discharged toward a residential/nursing home. Thus, high sensitivity, rather than specificity, was of utmost importance. However, choosing high sensitivity would decrease specificity and increase the proportion of inappropriate referrals-patients not requiring early and special discharge planning (false positives). A compromise had therefore to be found in order to maintain the proportion of patients referred for early discharge planning as low as possible (true positives plus false positives). A curve was thus drawn, plotting the sensitivity and the proportion of patients considered at high risk of discharge to residential/nursing home (true positives plus false positives) for the full range of possible thresholds. A suitable threshold would give the smallest proportion of patients considered at high risk of discharge to a residential/nursing home for a clinically acceptable sensitivity (about $75 \%$ ).

\section{INITIAL TESTING OF THE INDEX}

The total correct classification derived from the same set of data is biased because individuals were used both to develop and calculate the performance of the index. One way of estimating the classification bias is to remove an individual from the data, re-estimate the model parameters, and then classify this individual based on the new estimated parameters, and so on, for all individuals in the data set. The bias estimation was thus calculated by the difference between the correct classification derived from the data set and the correct classification obtained after removing each of all individuals. ${ }^{25}$

\section{Results}

Of the 417 patients included in the analysis, data were complete for $354(84.9 \%)$. Among these, $133(37.6 \%)$ were discharged to a residential/nursing home and $221(62.4 \%)$ discharged home.

The results of the stepwise fitting procedure of the logistic regression model produced from the 354 patients with complete data are shown in table 2. The factors, in order of inclusion in the final model, were:

1. Principal carer's wish,

2. Presence of a chronic condition suspected as being fatal or non-fatal within four years,

3. Ability to perform "toileting" (going to the lavatory for bowel and urine elimination; cleaning oneself afterwards, and arranging clothes),

4. Age,

5. Ability to know the name of the place (name of the hospital or the city) and

6. Living arrangements.

The factor most predictive of discharge to a residential/nursing home was the principal 
Table 2 Factors associated with discharge to a residential/nursing home of elderly patients admitted through the emergency department to two teaching hospitals in Paris (stepwise multiple logistic regression)

\begin{tabular}{|c|c|c|}
\hline Independent variables & $\beta$ coefficient & $\begin{array}{l}\text { Odds ratios } \\
(95 \% \text { CI) }\end{array}$ \\
\hline $\begin{array}{l}\text { Principal carer's wishes about patient returning home: } \\
\text { Agreement }(=0) \\
\text { Without opinion }(=1) \\
\text { Opposition }(=2)\end{array}$ & 1.00 & $\begin{array}{l}1 \\
2.7(1.8,4.1) \\
7.4(3.3,16.4)\end{array}$ \\
\hline Chronic condition: & 0.60 & \\
\hline $\begin{array}{l}\text { None }(=0) \\
\text { Yes, non-fatal within } 4 \text { years }(=1) \\
\text { Yes, fatal within } 4 \text { years }(=2)\end{array}$ & & $1.8(1.2,2.8)$ \\
\hline $\begin{array}{l}\text { Yes, fatal within } 4 \text { years }(=2) \\
\text { Ability to perform toileting: }\end{array}$ & 0.62 & \\
\hline $\begin{array}{l}\text { Independent }(=0) \\
\text { Dependent }(=1)\end{array}$ & & $1.5(1.1,3.1)$ \\
\hline $\begin{array}{l}\text { Age }(\mathrm{y}): \\
\leq 85(=0) \\
>85(=1)\end{array}$ & 0.52 & $17(1,127)$ \\
\hline $\begin{array}{l}\text { Ability to know the name of place*: } \\
\text { Correct answer }(=0) \\
\text { Incorrect answer }(=1)\end{array}$ & 0.64 & $1.9(1.1,3.3)$ \\
\hline $\begin{array}{l}\text { Living alone: } \\
\text { No }(=0) \\
\text { Yes }(=1)\end{array}$ & 0.55 & $1.9(1.2,3.3)$ \\
\hline
\end{tabular}

* The answer was considered as correct if the patient gave correctly the name of the hospital or the city.

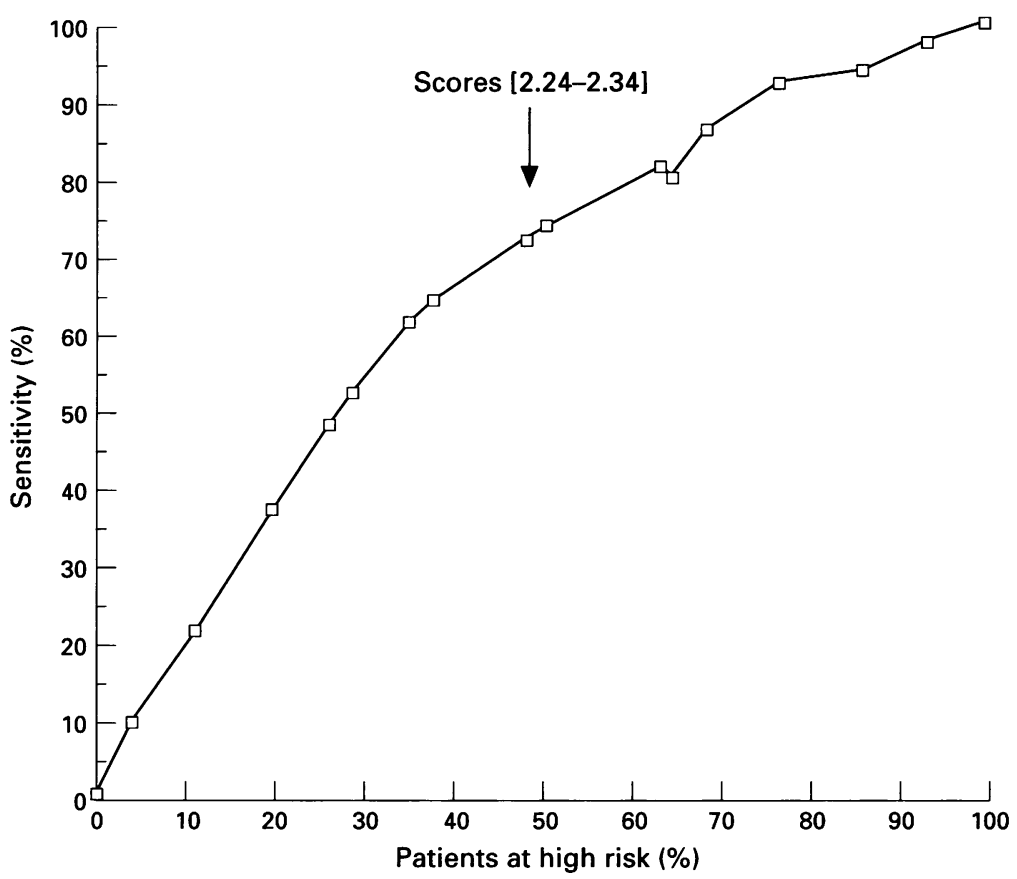

Figure 1 Proportion of patients considered to be at high risk of discharge to a residential or nursing home.

Table 3 Change in the initial coefficients of the final logistic model by simplified coefficients (round numbers)

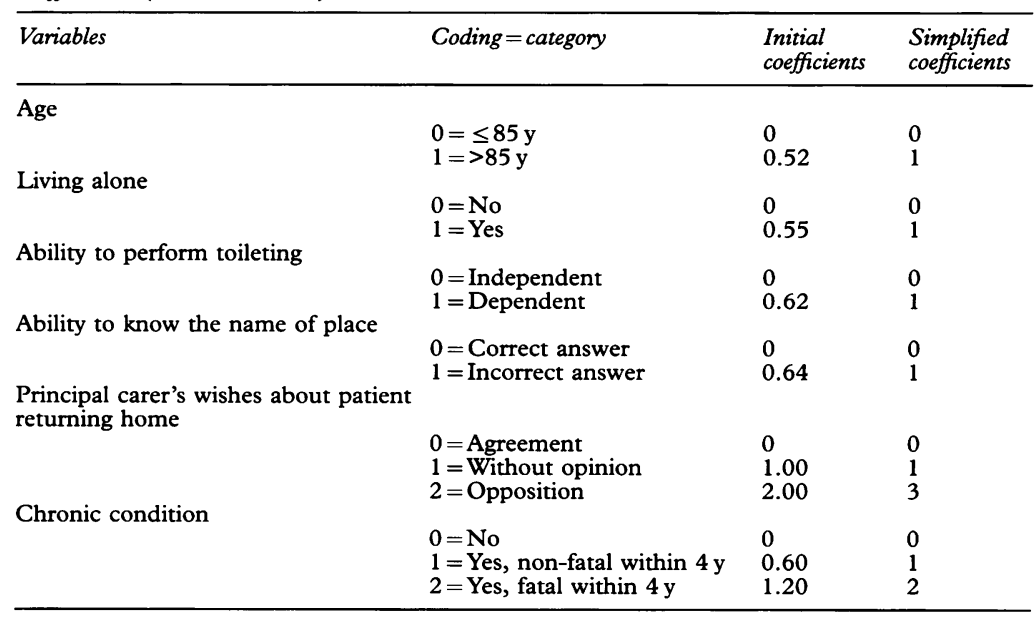

carer's wishes about the patient returning home after acute hospitalisation. When the principal carer was opposed to the patient returning home, the patient's probability of being discharged to a residential/nursing home was seven times that of a patient with a principal carer who agreed to their returning home ( $\mathrm{OR}=7.4,95 \%$ confidence interval (CI) 3.2, 16.4). The ability to perform toileting was the ADL item and the ability to know the name of the place was the SPMSQ item which were related to outcome of hospitalisation.

The $\mathrm{p}$ value for the Hosmer-Lemeshow goodness-of-fit test was 0.476 , indicating an acceptable degree of calibration between model performance and actual outcome of hospitalisation.

The choice of the discriminant threshold was made from the curve relating the sensitivity to the proportion of patients considered by the model to be at high risk of discharge to a residential/nursing home. Corresponding to a sensitivity of around $75 \%$, a range of thresholds (2.24-2.34) was considered acceptable (fig 1).

The model was intended to be used for medical management without a sophisticated hand calculator or computer and so the score's calculation had to be simplified. To produce a simplified score for each patient, we replaced the initial coefficients of the index with round numbers $-0,1,2,3$ (table 3 ). Then, we made a numeric correspondence between the initial score and the simplified score for all possible combinations of the categories of variables. There were 10 thresholds (initial scores: 0, $0.52,1.07,1.67,2.27,2.89,3.53,4.27,4.89$, 5.53; corresponding simplified scores: $0,1,2$, $3,4,5,6,7,8,9)$ where the choices were equivalent. One of them (2.27) was in the range of thresholds (2.24-2.34) considered as acceptable. The choice of 2.27 as a threshold in the initial score was equivalent to the choice of 4 as a threshold in the simplified score. The sensitivity of this threshold was $74.4 \%$, the specificity $63.8 \%$, the predictive power of the positive test $57.8 \%$, the predictive power of the negative test $80.6 \%$, the total correct classification $67.8 \%$, and $50.6 \%$ of patients were considered at high risk of discharge to a residential/nursing home (table 4 ).

INITIAL TESTING OF THE INDEX

After removing each of the 354 patients from the data, re-estimating the parameters of the model, and then classifying each of the patients based on the corresponding new parameters estimated, the correct classification was $67.2 \%$ (table 5). Thus, the bias estimation was $0.6 \%$.

Another statistical technique was also applied to test the statistical validation of the index. The population was split into two independent populations of approximately two thirds and one third, respectively. The first 210 patients with complete data were used to develop the index (the derivation set). The last 144 patients were used to test the index performance in an independent population (the test set). In the derivation set, the final logistic model included the same six variables which were entered in the 
Table 4 Prediction of outcome of hospitalisation in elderly patients admitted through the emergency department to two teaching hospitals in Paris using the index with a threshold score of 2.27 (simplified score $=4$ )

\begin{tabular}{|c|c|c|c|}
\hline Score & \multicolumn{2}{|l|}{ Outcome of hospitalisation } & \multirow{2}{*}{$\begin{array}{l}\text { Total } \\
(n=354)\end{array}$} \\
\hline Simplified & $\begin{array}{l}\text { Residential/nursing home } \\
(n=133)\end{array}$ & $\begin{array}{l}\text { Home } \\
(n=221)\end{array}$ & \\
\hline $\begin{array}{l}\geq 2.27 \quad \geq 4 \\
\text { (Considered at high risk of discharge } \\
\text { to a residential/nursing home) } \\
<2.27 \\
\text { (Considered at low risk of discharge } \\
\text { to a residential/nursing home) }\end{array}$ & 34 & 141 & 179 \\
\hline
\end{tabular}

Sensitivity $(99 / 133)=74.4 \%$; specificity $(141 / 221)=63.8 \%$; predictive power of a positive test (99/ $179)=55.3 \%$; predictive power of a negative test $(141 / 175)=80.6 \%$; total correct classification $(99+141 / 354)=67.8 \%$.

Proportion of patients considered at high risk $=(99+80 / 354)=50.1 \%$.

Table 5 Prediction of outcome of hospitalisation in elderly patients admitted through the emergency department to two teaching hospitals in Paris: initial testing of the index

\begin{tabular}{|c|c|c|c|}
\hline Score & \multicolumn{2}{|l|}{ Outcome of hospitalisation } & \multirow{2}{*}{$\begin{array}{l}\text { Total } \\
(n=354)\end{array}$} \\
\hline Simplified & $\begin{array}{l}\text { Residential/nursing home } \\
(n=133)\end{array}$ & $\begin{array}{l}\text { Home } \\
(n=221)\end{array}$ & \\
\hline $\begin{array}{l}\geq 2.27 \\
\text { (Considered at high risk of discharge } \\
\text { to a residential/nursing home) }\end{array}$ & 97 & 80 & 177 \\
\hline $\begin{array}{l}<2.27 \\
\text { (Considered at low risk of discharge } \\
\text { to a residential/nursing home) }\end{array}$ & 36 & 141 & 177 \\
\hline
\end{tabular}

Sensitivity $(99 / 133)=72.9 \%$; specificity $(141 / 221)=63.8 \%$; predictive power of the positive test $(97 / 177)=54.8 \%$; predictive power of the negative test $(141 / 177)=79.7 \%$; proportion of patients considered at high risk $=(97+80 / 354)=50.0 \%$; total correct classification $(97+141 / 354)=$ $67.2 \%$. the 30 patients with missing data. The sensitivity was $75.0 \%$ and the specificity $64.3 \%$. These values were comparable to those obtained from patients with complete data.

\section{Discussion}

The objective of this study was to develop, shortly after hospital admission, a simple index which could be used to identify those patients who were unable to return home immediately after acute hospitalisation (more frequent users of health care resources). For these patients, early discharge planning including medical and/ or social intervention, coordination of services, and early negotiation with institutions might lead to a more effective management process, reduce the length of hospitalisation, and prevent unnecessary re-admission or nursing home placement. ${ }^{5-726}$ The index was built on six factors: the principal carer's wishes about the patient returning home after acute hospitalisation, the presence of a chronic condition fatal or non-fatal within four years, the ability to perform toileting, the ability to know the name of the hospital or the city, age, and living arrangements. These factors were medical, functional, and social in nature. Five of them were easily obtainable within 24 hours of admission to hospital and an additional one was ascertainable within 48 hours (principal carer's wishes). All variables were clearly and well defined and some were routinely evaluated on admission for each patient. Collecting the data necessary to calculate the score was simple and rapid. The score has become easy to obtain after simplifying the score's calculation.

In our study, the most important predictor of hospitalisation outcome was the opposition of the principal carer to the patient returning home. This was in agreement with previous work. ${ }^{14}$ Furthermore, several studies have shown that advancing age, ${ }^{40-1214}$ impaired cognitive function, ${ }^{41012131516}$ ADL dysfunction, ${ }^{4101516}$ and living alone $\mathrm{e}^{461013}$ are related to nursing home and special care settings. We did not, however, find that gender and marital status were associated with an increased risk of discharge to an institution. Inconsistencies in research findings could be explained by differences in health care systems across countries, different sampling methods within each type of study design, and differences in methods of analysis. ${ }^{27}$ We were unable to find any association between the outcome of hospitalisation and the main reason for admission. Functional status measured by the ADL may be a better reflection of the impact of illnesses. ${ }^{28}$ The presence of a chronic condition considered fatal or non-fatal within four years was associated with the outcome of hospitalisation. This was assessed by a modified MacCabe indicator, ${ }^{22}$ which had proved to be reproducible during previous field testings. ${ }^{29}$

The index with a critical score of 2.27 (simplified score 4) succeeded in identifying threequarters of patients who were ultimately discharged to a residential/nursing home. The sensitivity obtained $(74.4 \%)$ was judged acceptable because factors included in the model 
were chosen from those available very shortly after admission, neglecting conditions which occurred during the hospitalisation. The index failed to identify a quarter of patients at high risk of discharge to a residential/nursing home (false negatives). These patients would benefit from the routine discharge planning as is provided nowadays. About half the patients were considered at high risk of discharge to a residential/nursing home. Of these, only $55 \%$ (predictive power of the positive test) would actually need special and early discharge planning. This fact was considered as acceptable with regard to the benefits resulting from early discharge planning for patients in need of special placement.

Since the procedures for discharge planning are different for subjects admitted to an acute care hospital from a residential/nursing home, this study was confined to patients admitted from home. Patients who died or were transferred and those for whom data was incomplete were excluded from the present analyses. As with any system based on clinical measurement, missing values present a problem. However, complete data were available for 354 patients $(84.9 \%)$ and the index would be applicable to 30 patients with missing data. Thus, decisions were possible for a total of 384 patients (92.1\%). Obviously, there was no information available on the outcome of hospitalisation (discharge toward an institution or home) for the 71 subjects who died. Since the aim of the study was not to identify subjects who died in the course of hospitalisation, we did not analyse that aspect. In contrast, it was important to assess the number of dead subjects who would have been considered at high risk of discharge to a residential/nursing home $(29 / 71,40.8 \%)$. Thus, early discharge planning would have been asked for an additional $7 \%$ of patients. However, this unnecessary workload could be considered as minor when compared with the possible benefits resulting from early discharge planning for patients placed in an institution. Patients who were transferred to other acute care facilities were also excluded as discharge planning would then be the responsibility of another acute care team.

Evans et al have developed an index from variables available at the hospital admission to determine the risk for placement, readmission, or lengthy stay. ${ }^{30}$ The factors that determined the outcome of hospitalisation included: two or more chronic medical conditions, living alone or being admitted from a nursing home, dependent ambulation, poor mental status, psychiatric comorbidity, prior admission to hospital, age over 75 years, and being unmarried. Although the index had sensitivity and specificity similar to ours, types of outcome were not studied separately and this index contains a higher number of items $(n=8)$ which were identified by univariate analysis. With similar results, Inui et al using the Glass CAAST index were able to identify patients in need of planning for nursing home placement. ${ }^{31}$ In this study the population was much younger (mean age 59 years, range 20-98), the proportion of males was $98 \%$, and only $9 \%$ of patients required special placement at discharge. ${ }^{31}$

An index predicting the hospitalisation outcome for elderly patients shortly after admission was therefore developed for our study population. However, the performance of the index was not tested in a population other than that in which it was developed and this study should be seen only as a first step in producing the index. Thus, validation of the index is needed and the first question should be assessment of its predictive capabilities in measuring what it is supposed to measure in other populations and in other hospitals. The second step to take is to determine if some improvement in quality of care results from using the index. Our hypothesis was that identifying, shortly after admission, those patients who will need geriatric and social assistance could shorten the length of hospital stay. However, this hypothesis remains to be tested. If it is true, some adverse effects of hospital stays, for which elderly people are at high risk, might be avoided. ${ }^{32}$

This work was supported in part by grants from the Direction Générale de la Santé and from the Assistance Publique/ Hôpitaux de Paris.

We are grateful for the help of Drs $\mathbf{B}$ de Corbière, $\mathbf{N}$ d'Oliveira the social workers of Pitié and Bichat hospitals, D Meslage, the social worker We also thank A Bingham for reviewing the manuscript.

1 Andrews K, Brocklehurst JC. The implications of demographic changes on resource allocation. $\mathcal{F} R$ Coll Physicians graphic changes on reso
Lond 1985;19:109-11.

2 Médina S, Ledésert B. La morbidité hospitalière en Ile-deFrance: synthèse régionale. Paris: Observatoire Régional de Santé d'Ile-de-France, 1991:179.

3 Béland F, Lemay A, Philibert L, Maheux B, Gravel G. Elderly patients' use of hospital-based emergency services. Med Care 1991;29:408-18.

4 Shapiro E, Tate RB, Roos NP. Do nursing home reduce hospital use? Med Care 1987;25:1-8.

5 Saltz CC, McVey LJ, Becker PM, Feussner JR, Cohen HJ. Impact of a geriatric consultation on discharge placement and repeat hospitalization. Gerontologist 1988;28:345-49.

6 Ledésert B, Lombrail P, Yéni P, Carbon C, Brodin M. The impact of a comprehensive multi-dimensional geriatric assessment programme on duration of stay in a French assessment programme on duration of stay in a
acute medical ward. Age Ageing 1994;23:223-27.

7 Rubenstein LZ, Josephson KR, Wieland GD, English PA, Kane RL. Effectiveness of a geriatric evaluation unit. A Glass R, Weiner M. Seeking a social disposition for the medical patient: CAAST, a simple and objective clinical index. Med Care 1976;14:637-44.

9 Barberger-Gateau P, Dabis F, Moise A, Gimbert M, Galley $P$, Salamon R. Facteurs liés - la durée d'hospitalisation des personnes âgées en court séjour. Rev Epidém Santé Publ 1987;35:463-73.

10 Branch LG, Jette AM. A prospective study of long-term care institutionalization among the aged. $A m \mathcal{F}$ Public Health 1982;72:1373-79.

11 Lamont CT, Sampson S, Matthias R, Kane RL. The outcome of hospitalization for acute illness in the elderly. $\mathcal{f}$ Am Geriatr Soc 1983;31:282-8.

12 Kane RL, Matthias R, Sampson S. The risk of placement in a nursing home after acute hospitalization. Med Care in a nursing hom

13 Barberger-Gateau P, Grolier L, Maurice S, Borde C, Salamon R, Galley P. L'hospitalisation en court-séjour des personnes âgées: premier pas vers l'entrée en institution. Rev Epidém Santé Publ 1990;38:323-32.

14 Roudot-Thoraval F, Boubert M, Fouresite V, Lejonc JL. Social future of elderly admitted to acute care hospital: opinion of patient or family as predictive factor of subsequent transfer to long term care. BMF 1987;294:608-9.

15 Wachtel TJ, Derby C, Fulton JP. Predicting the outcome of hospitalization for elderly persons: home versus nursing home. South Med f 1984;77:1283-5.

16 Narain P, Rubenstein LZ, Wieland GD, Rosbrook B, Strome LS, Pietruszka F, Morley JE. Predictors of immediate and 6-month outcomes in hospitalized elderly patients. The importance of functional status. I Am Geriatr Soc 1988; 6:775-83.

17 Zureik M, Lang T, Trouillet JL, Davido A, Tran B, Levy B, Lombrail P. Returning home after acute hospitalization in two French teaching hospitals: predictive value of patients' and relatives' wishes. Age Ageing 1995;24:22734 . 
18 Katz S. Assessing self-maintenance: activities of daily living, mobility and instrumental activities of daily living. $\mathcal{F} \mathrm{Am}$ Geriatr Soc 1962;110:83-91.

19 Lawton PM, Brodie EM. Assessment of older people self maintening and instrumental activities of daily living. Gerontologist 1969;8:179-86.

20 Pfeiffer E. A short portable mental status questionnaire for the assessment of organic brain deficit in elderly patients. f Am Geriatr Soc 1975;23:433-41.

21 WHO. Ineternational classification of diseases. 9th rev. Geneva: WHO, 1975.

22 McCabe WR, Jackson GG. Gram-negative bacteriemia Arch Int Med 1962;110:83-91.

23 Hosmer DW, Lemeshow S. Applied logistic regression. New York: John Wiley \& Sons, 1989

24 SAS. SAS user's guide: statistics. Version 6, 4th ed. Cary, NC: SAS, 1990

25 Lachenbruch PA, Ray Mickey M. Estimation of error rates in discriminant analysis. Technometrics 1968;10:1-11.

26 Leth Landefeld C, Palmer R, Kresevic D, Fortnsky RH Kowal J. A randomized trial of care in a hospital medical unit especially designed to improve the functional out- comes of actually ill older patients. $N$ Engl $f$ Med 1995 ; 332:1338-44.

27 Wingard DL, Jones DW, Kaplan RM. Institutional care utilization by the elderly: a critical review. Gerontologis

28 Kaplan RM, Atkins CJ, Timms RM. Validity of a quality of well-being scale as an outcome measure in chronic obstructive pulmonary disease. $\mathcal{f}$ Chronic Dis 1984;37: 85-95.

29 De Corbière B. Utilisation d'indicateurs permettant - l'équipe soignante d'estimer le devenir des personnes âgées hospitalisées: enquête au service porte de l'hôpital Bichat. Bobigny: 1993. Medical dissertation.

30 Evans RL, Hendricks RD, Lawrence KV, Bishop DS. Identifying factors associated with health care use: a hospitalbased risk screening index. Soc Sci Med 1988;27:947-54

31 Inui TS, Stevenson KM, Plorade D, Murphy I. Identifying hospital patients who need early discharge planning for special dispositions: need early discharge planning for special dispositions: a comparison
niques. Med Care 1981;29:922-29.

32 Leape LL, Brenan TA, Laird N, et al. The nature of adverse events in hospitalized patients. Results of the Harvard medical practice study II. $N$ Engl $\mathcal{F}$ Med 1991;324:377-84. 